\title{
Evaluation of potential reference genes for quantitative RT- PCR analysis in spotted sea bass (Lateolabrax maculatus) under normal and salinity stress conditions
}

\author{
Haolong Wang ${ }^{1,2}$, Haishen Wen ${ }^{1,2}$, Yun Li ${ }^{\text {Corresp.. }}{ }^{1,2}$, Kaiqiang Zhang ${ }^{1,2}$, Yang Liu ${ }^{1,2}$ \\ ${ }^{1}$ College of Fisheries, Ocean University of China, Qingdao, China \\ 2 The Key Laboratory of Mariculture (Ocean University of China), Ministry of Education, Ocean University of China, Qingdao, China \\ Corresponding Author: Yun Li \\ Email address: yunli0116@ouc.edu.cn
}

The aim of this study was to select the most suitable reference genes for quantitative realtime polymerase chain reaction (qRT-PCR) of spotted sea bass (Lateolabrax maculatus), an important commercial marine fish in Pacific Asia, under normal physiological and salinity stress conditions. A total of 9 candidate reference genes (HPRT, GAPDH, EFIA, TUBA, RPL7 , RNAPol II , B2M, ACTB and 18S rRNA) were analyzed by qRT-PCR in 10 tissues (intestine, muscle, stomach, brain, heart, liver, gill, kidney, pectoral fins and spleen) of $L$. maculatus. Four algorithms, geNorm, NormFinder, BestKeeper, and comparative $\Delta \mathrm{Ct}$ method, were used to evaluate the expression stability of the candidate reference genes. The results showed the 18S rRNA was most stable in different tissues under normal conditions. During salinity stress, RPL7 was the most stable gene according to overall ranking and the best combination of reference genes was RPL7 and RNAPol II. In contrast, GAPDH was the least stable gene which was not suitable as reference genes. The study showed that different algorithms might generate inconsistent results. Therefore, the combination of several reference genes should be selected to accurately calibrate system errors. The present study was the first to select reference genes of $L$. maculatus by qRT-PCR and provides a useful basis for selecting the appropriate reference gene in L. maculatus. The present study also has important implications for gene expression and functional genomics research in this species or other teleost species. 


\section{Evaluation of potential reference genes for quantitative RT-PCR}

\section{2 analysis in spotted sea bass (Lateolabrax maculatus) under}

\section{3 normal and salinity stress conditions}

4 Haolong Wang ${ }^{1,2}$, Haishen Wen ${ }^{1,2}$, Yun Li ${ }^{1,2}$, Kaiqiang Zhang ${ }^{1,2}$, Yang Liu ${ }^{1,2}$

$5{ }^{1}$ College of Fisheries, Ocean University of China, Qingdao, China

$6 \quad{ }^{2}$ The Key Laboratory of Mariculture (Ocean University of China), Ministry of Education, Ocean

7 University of China, Qingdao, China.

9 The corresponding Author:

10 Yun $\mathrm{Li}^{1,2}$

115 Yushan Road, Qingdao 266003, China

12 E-mail: yunli0116@ouc.edu.cn 


\section{Abstract}

The aim of this study was to select the most suitable reference genes for quantitative realtime polymerase chain reaction (qRT-PCR) of spotted sea bass (Lateolabrax maculatus), an important commercial marine fish in Pacific Asia, under normal physiological and salinity stress conditions. A total of 9 candidate reference genes (HPRT, GAPDH, EF 1A, TUBA, RPL7, RNAPol $I I, B 2 M, A C T B$ and $18 S r R N A$ ) were analyzed by qRT-PCR in 10 tissues (intestine, muscle, stomach, brain, heart, liver, gill, kidney, pectoral fins and spleen) of L. maculatus. Four algorithms, geNorm, NormFinder, BestKeeper, and comparative $\Delta \mathrm{Ct}$ method, were used to evaluate the expression stability of the candidate reference genes. The results showed the $18 S$ rRNA was most stable in different tissues under normal conditions. During salinity stress, RPL 7 was the most stable gene according to overall ranking and the best combination of reference genes was $R P L 7$ and $R N A P o l$ II. In contrast, GAPDH was the least stable gene which was not suitable as reference genes. The study showed that different algorithms might generate inconsistent results. Therefore, the combination of several reference genes should be selected to accurately calibrate system errors. The present study was the first to select reference genes of $L$. maculatus by qRT-PCR and provides a useful basis for selecting the appropriate reference gene in L. maculatus. The present study also has important implications for gene expression and functional genomics research in this species or other teleost species.

\section{Introduction}

Quantifying gene expression levels is an essential research strategy to understand and reveal complex regulatory gene networks in organisms (Dekkers et al., 2005). Quantitative real-time PCR (qRT-PCR) is considered the most powerful and commonly used tool for analyzing the relative transcription levels in gene expression because of its advantages of easy accessibility and highthroughput and fast-processing. Additionally, qRT-PCR can detect the low abundance of transcripts and small changes in gene expression. To obtain reliable gene expression profiles, accurate transcript normalization by using the internal reference genes (housekeeping genes) is a necessary prerequisite. The optimal reference genes should be constant with the adjustment of the experimental procedure (tissues, treatments and developmental stages) (Radonić et al., 2004). However, the stability of the reference gene is relative, and the expression level of the reference gene used might commonly be unstable under different conditions (Gutierrez et al., 2008). No single gene maintained constant expression levels in all species and different tissues and under different experimental conditions. For example, $\beta$-Actin and $U B C E$ were the most stable genes in Japanese flounder (Paralichthys olivaceus) tissues, whereas $18 S$ rRNA showed the most stable expression in all embryonic developmental stages in P. olivaceus (Zheng \& Sun, 2011; Zhong et al., 2008). Therefore, it is necessary to select specific reference genes of species and tissues that 
could be helpful for studies on regulatory gene networks under different conditions.

The spotted sea bass, Lateolabrax maculatus, is a newly redescribed species (Yokogawa \& Seki, 1995; Kim et al., 2001; Liu et al., 2006; Yokogawa, 2013) with commercially significant value in the recreational fishery and mariculture industry in Pacific Asia. This fish is widely distributed along the Chinese coast, reaching south to the borders of Vietnam and north to Korea (Yokogawa \& Seki, 1995). Furthermore, as euryhaline species, the spotted sea bass is a valued fish model that could be cultured in fresh water after domestication. To date, considering its economic value, the expression levels of several potential trait-related function genes have been reported in L. maculatus, such as hypothalamus-pituitary-gonad (HPG) axis genes (Wang et al., 2017), heat shock protein 70 (HSP70) genes (Han et al., 2017). Moreover, the salinity stress-responsive transcriptome has also been analyzed (Zhang et al., 2017). In these reports, $\beta$-actin and $18 S$ rRNA, as traditional reference genes, have been used without validation for appropriateness. Moreover, $\beta$-actin, as an internal standard for gene expression quantitation, could show confounding results (Glare et al., 2002). Thus far, there is no validated reference gene reported in L. maculatus. Thus, it is necessary to identify and select suitable reference genes for the accurate analysis of gene expression in L. maculatus.

Stress in fish caused by abiotic factors encountered in nature and aquaculture, such as acidbase, salinity and temperature, leads to various responses that might be adaptive or maladaptive. Among these responses, salinity is a major abiotic factor that affects the growth, hatch, reproduction and survival of fish species (Imsland et al., 2001; Tandler, Anav \& Choshniak, 1995; Berlinsky et al., 2004). The ability to endure changes in salinity depends on the capacity to regulate osmotic pressure (Tandler, Anav \& Choshniak, 1995). Moreover, the gill, kidney and intestine are important osmoregulatory organs in fish to maintain the balance of ionic composition and osmolality of the fluid in teleosts (Katoh et al., 2000). Particularly, the gill is a functionally and morphologically complex tissue comprising plentiful, interconnected physiological activities, which are vital to maintaining systemic homeostasis in the face of changing internal and external environments (Evans, Piermarini \& Choe, 2005). For this reason, the present study was aimed to select suitable reference genes and evaluate the reference genes stability in L. maculatus among different tissues and under the salinity stress. A total of 9 reference genes, including $18 \mathrm{~s} r N A$, HPRT, GAPDH, EF1A, TUBA, RPL7, RNAPol II, B2M and ACTB, were selected. The present study could provide some theoretical basis for selecting reference genes in L. maculatus and other fishes.

\section{Materials and methods}

\section{Animals, treatments and fish sampling}

All animal experiments were conducted in accordance with the guidelines and approval of Institutional Animal Care and Use Committee of Ocean University of China. The field studies did not involve endangered or protected species.

Spotted sea bass $(786.53 \pm 18.28 \mathrm{~g})$, cultured in cages, were obtained from Jiaonan (Qingdao City, Shandong Province, China) and then transported to the laboratory. The fish were acclimatized 
114 at room temperature in seawater (30ppt) with continuous aeration for a week prior to experiment.

115 Nine healthy fish were randomly divided into 3 groups as three biological replicates. The fish were 116 treated with tricaine methanesulfonate (MS 222, $200 \mathrm{mg} / \mathrm{L}$ ) and immediately dissected. The 117 intestine, muscle, stomach, brain, heart, liver, gill, kidney, pectoral fins and spleen were collected. 118 Ten tissues per fish were numbered and stored at $-80^{\circ} \mathrm{C}$ for RNA extraction.

For the salinity challenge experiment, 60 spotted sea bass $(100.00 \pm 2.34 \mathrm{~g})$ were acquired from Shuangying Aquatic Seed Company (Lijin County, Dongying City, Shandong Province). The fish were acclimatized at a density of 5 individuals per tank $(120 \mathrm{~L})$. Water temperature, $\mathrm{pH}$, dissolved oxygen and light-dark cycle were maintained at $21^{\circ} \mathrm{C}\left( \pm 0.5^{\circ} \mathrm{C}\right), 7.98 \sim 8.04,6.90 \sim 8.54$ $\mathrm{mg} / \mathrm{L}$ and $14 \mathrm{~L}: 10 \mathrm{D}$, respectively. After acclimation, the fish were randomly divided into 4 groups with different salinities $(0,12,30$, and $45 \mathrm{ppt})$. After rearing for 30 days, 9 fishes per group were randomly selected as three biological replicates and treated with MS $222(200 \mathrm{mg} / \mathrm{L})$. Gill tissues were immediately frozen in liquid nitrogen and then stored at $-80^{\circ} \mathrm{C}$ until further use.

\section{RNA extraction and cDNA synthesis}

Two experimental sample sets were constructed. Set A: different tissues (intestine, muscle, stomach, brain, heart, liver, gill, kidney, pectoral fins, and spleen) and set B: different salinities ( 0 , $12,30$, and $45 \mathrm{ppt})$. The total RNA was extracted from samples by using TRIzol reagent (Invitrogen, USA) according to the manufacturer's instructions and digested with RNase-free DNase I (TaKaRa, Japan) to remove genomic DNA contamination. Equal amounts of RNA from the same tissues of 3 individual fish under the same conditions were pooled as one sample to minimize the variation among individuals, and three such pools were obtained for each tissue and salinity treatment group. The concentration was determined by nucleic acid protein analyzer BD1000 (Beijing, China), and the quality of RNA was assessed by gel electrophoresis. Samples with 260/280 absorbance ratios greater than 1.9 were used for cDNA synthesis. A $0.5-\mu \mathrm{g}$ aliquot of total RNA from each sample was reverse transcribed by using the PrimeScript ${ }^{\mathrm{TM}}$ RT reagent Kit with gDNA Eraser (TaKaRa, Japan) employing a RT Primer MIX (Random 6 mers and Oligo dT Primer) in a $20 \mu 1$ reaction according to the manufacturer's instructions. The synthesized cDNA was stored at $-20^{\circ} \mathrm{C}$.

\section{Selection of reference genes for spotted sea bass}

Nine reference genes were selected for gene expression analysis, including the reference gene ( $18 S$ rRNA) sequences from the GenBank database (https://www.ncbi.nlm.nih.gov/genbank/) and 8 reference genes sequences from transcriptomics database by the IlluminaHiseq 4000 platform. The abbreviated and full gene names and the GenBank accession numbers are provided in Table 1.

\section{Primers design and qRT-PCR}

All reference gene primers were designed by the Primer 5.0 software. Nine primer pairs were synthesized by the Beijing Genomics Institute (BGI) and tested via standard RT-PCR by using six serial five-fold dilutions of sample cDNA with $\mathrm{SYBR}^{\circledR}$ Premix Ex Taq ${ }^{\mathrm{TM}}$ (TaKaRa, Japan). The 
152 specificity of amplification was verified by melting curve and agarose gel electrophoresis, and the 153 primer amplification efficiency was calculated as $\mathrm{E}(\%)=\left(10^{(-1 / \mathrm{slopes})}-1\right) \times 100($ Pfaffl, 2001). The 154 qRT-PCR was performed in 96-well plates by using the StepOne Plus Real-Time PCR system 155 (Applied Biosystems). The reaction $(20 \mu \mathrm{l})$ was performed by using SYBR ${ }^{\circledR}$ Premix Ex Taq ${ }^{\mathrm{TM}}$ 156 (TaKaRa, Japan). Each well contained $10 \mu \mathrm{l}$ of SYBR ${ }^{\circledR}$ Premix Ex Taq ${ }^{\mathrm{TM}}, 0.4 \mu \mathrm{l}$ of ROX 157 Reference Dye, $6.8 \mu 1$ of sterilized ddH2O, $0.4 \mu 1$ of each primer $\left(10 \mu \mathrm{mol} \mathrm{L}^{-1}\right)$, and $2 \mu 1$ of cDNA 158 template. The reaction conditions were $95^{\circ} \mathrm{C}$ for $30 \mathrm{~s}$, followed by 40 cycles at $95^{\circ} \mathrm{C}$ for $5 \mathrm{~s}$ and $15960^{\circ} \mathrm{C}$ for $30 \mathrm{~s}$. After PCR amplification, a melting curve was obtained by the following process: $16095^{\circ} \mathrm{C}$ for $5 \mathrm{~s}, 60^{\circ} \mathrm{C}$ for $1 \mathrm{~min}$, followed by $95^{\circ} \mathrm{C}$ at the rate of $0.11^{\circ} \mathrm{C}$ per second to verify primer 161 specificity. All RT-qPCR assays were carried out in three biological replicates with three technical 162 replicates.

\section{Statistical analysis}

The expression stability of the 9 reference genes was evaluated by 4 different algorithms: geNorm (Vandesompele et al., 2002), NormFinder (Andersen, Jensen \& Ørntoft, 2004), BestKeeper (Pfaffl, et al., 2004), and comparative $\Delta \mathrm{Ct}$ method (Silver, et al., 2006). The comprehensive ranking of candidate reference genes was evaluated by calculating the geometric mean of each reference gene ranking (Chen, et al., 2011). The raw $\mathrm{Ct}$ values in geNorm and NormFinder were previously transformed to relative quantities (RQ). RQ $=(1+\mathrm{E}){ }^{\Delta \mathrm{Ct}}, \Delta \mathrm{Ct}=$ lowest $\mathrm{Ct}$ value - $\mathrm{Ct}$ value of sample. $\mathrm{E}$ is equal to 2 when PCR efficiencies approach $100 \%$. The highest relative quantities for each gene are set to 1. Finally, all the reference genes were ranked by four programs. Then, all graphs were generated by using SPSS 19.0 and OriginPro 8.0.

\section{Results}

\section{Amplification efficiencies of primers}

A single peak was obtained in each amplification during the analysis of the melting curves after 40 cycles by the Applied Biosystems StepOne Plus Real-Time PCR system (Figure S1), and agarose gel electrophoresis showed that each of the amplifications products was a single band of the expected size (Figure S2). The primer efficiency (E) and correlation coefficients $\left(\mathrm{R}^{2}\right)$ were determined based on the standard curves. The primer efficiency $(\mathrm{E})$ of the nine genes ranged from $94.16 \%$ to $106.67 \%$, and the correlation coefficients $\left(\mathrm{R}^{2}\right)$ ranged from 0.9966 to 0.9994 (Table 2).

\section{Transcription levels of candidate reference genes}

The transcription levels of all 9 candidate reference genes were assessed by qRT-PCR. The raw $\mathrm{Ct}$ values showed different variation and transcription levels. In different tissues, the coefficient of variation $(\mathrm{CV})$ of the raw $\mathrm{Ct}$ values was calculated to evaluate transcription level variations. The $\mathrm{CV}$ of all reference genes ranged from 4.011 to $17.550 \%$, and the $\mathrm{Ct}$ values varied from 9.402 to 34.015. GAPDH and RNAPol II were the most variable and the least variable reference genes, respectively. Among these reference genes, $18 S$ rRNA showed the highest transcription level (average $\mathrm{Ct}=10.360$ ), while $R N A$ Pol II showed the lowest expression level 
189 (average $\mathrm{Ct}=26.399$ ). The expression trend of these candidate reference genes in the samples after

190

191

192

193

194

195

196

197

198

199

200

201

202

203

204

205

206

207

208

209

210

211

212

213

214

215

216

217

218

salinity treatment was similar to that in different tissues, and the $\mathrm{CV}$ of all reference genes ranged between 1.078 to $3.830 \%$ and $\mathrm{Ct}$ values varied from 9.661 to 28.133. GAPDH displayed the highest transcription-level variation. The lowest transcription level variation was observed for $H R P T$, followed by RPL7 and RNAPol II. The minimum mean Ct value was 10.386 , and the maximum mean $\mathrm{Ct}$ value was 26.517 for the highest and lowest expression levels for $18 S R R A$ and GAPDH (Figure 1).

\section{Evaluation of stability of the candidate reference genes}

To select optimal reference genes for accurate normalization under the same experimental conditions, four common algorithms were used to analyze expression stability and rank the reference genes.

\section{geNorm analysis}

geNorm defined the $\mathrm{M}$ value as expression stability measure, which describes the average pairwise variation of a candidate gene relative to all other candidate genes. The tested sample gene with lowest $M$ value shows the most stable expression and vice versa. In the present study, the expression stability $\mathrm{M}$ value of 9 candidate reference genes was calculated by the geNorm program. Among different tissues, $18 S r R N A$ and $A C T B$ have the least $\mathrm{M}$ value of 0.90 , while $G A P D H$ showed the highest value, indicating that $18 S$ rRNA and $A C T B$ were most stable in expression and that $G A P D H$ was the least stable in expression. Furthermore, on the basis of geNorm analysis, the default limit of the stability value (M) is $<1.5$; thus, GAPDH, HRPT and $B 2 M$, with stability values $(\mathrm{M})$ above 1.5 , were not selected in gene expression. However, under salinity stress, the stability values $(\mathrm{M})$ of all candidate reference genes were below 1.5. RNAPol II and TUBA were the most stable genes, with $\mathrm{M}$ values of 0.16 , while $G A P D H$ was the least stable gene, with an $\mathrm{M}$ value of 0.67 . Thus, the geNorm analysis indicated that $18 S \mathrm{rRNA}$ and $A C T B$ were the most stable reference genes among different tissues, and RNAPol II and TUBA were the most stable genes in samples under salinity treatments, whereas $G A P D H$ was the least stable gene in both experimental sets (Figure 2).

It is important to determine the optimal number of genes for accurate normalization in qRTPCR. The geNorm algorithm was based on the analysis of the pairwise variation $\left(V_{n} / V_{n+1}\right)$ of sequential normalization factors to determine the optimal number of reference genes. The cutoff limit was set as 0.15 for pairwise variation, below which the addition of more genes is not necessary. For both experimental sets, in different tissues, all the pairwise variation $\left(\mathrm{V}_{\mathrm{n}} / \mathrm{V}_{\mathrm{n}+1}\right)$ was above 0.15 . The inclusion of the sixth gene had approximately the same effect $\left(V_{5} / V_{6}=0.217\right)$ on the NF as the inclusion of the eighth gene $\left(\mathrm{V}_{7} / \mathrm{V}_{8}=0.204\right)$ had. Therefore, no stable combination was desirable for the selected reference genes in different tissues. However, under salinity stress, all pairwise variation $(\mathrm{Vn} / \mathrm{Vn}+1)$ was below 0.15 , and the $\mathrm{V}_{2} / \mathrm{V}_{3}$ was well below 0.15 . Thus, two genes (RNAPol II and TUBA) had the optimal number combination under salinity stress (Figure 3).

\section{NormFinder analysis}

The NormFinder algorithm could also estimate the expression stability and rank the genes 
229

230

231

232

233

234

235

236

237

238

239

240

241

242

243

244

245

246

247

248

249

250

251

252

253

254

255

256

257

258

259

260

261

262

263

264

265

266

267

268

according to stability, which was based on the estimation of intra- and inter-group variations. The gene with the lowest stability value is considered to show the most stable expression and vice versa. As the NormFinder analysis showed, the optimal combinations were similar to the results obtained by geNorm, with slight differences. In different tissues, $18 S$ rRNA $(0.738)$ was the most stable gene, followed by RNAPol II (0.760), while GAPDH (2.981) was the least stable gene (Figure 4A). During salinity stress, RPL7 (0.166) and RNAPol II (0.235) were the most stable genes, while GAPDH (0.590) was the least stable gene (Figure 4B). The estimation of intra- and inter-group variations was also obtained (Table S1).

\section{BestKeeper analysis}

The BestKeeper algorithm estimates the expression stability of candidate genes by calculating and comparing the variation, including the coefficient of variance (CV) and standard deviation (SD). The most stable reference gene was selected based on the size of the SD value. The SD values of the candidate reference genes were negatively correlated with the stability of the gene, indicating that the lowest SD value shows the highest stability. Similarly, the results for different tissues by BestKeeper were highly similar to those obtained by geNorm and NormFinder. For example, $18 \mathrm{~S}$ $r R N A$ was the most stable gene, followed by $A C T B$, with an SD value $<1$, while $G A P D H$, with an SD value of 4.357, had the lowest stability. However, RPL7 was identified as the most stable gene, whereas $G A P D H$ was the least stable gene under salinity stress (Table 3 ).

\section{Comparative $\Delta \mathrm{Ct}$ method}

The comparative $\Delta \mathrm{Ct}$ method identifies optimal candidate genes by comparing the relative expression of a pair of genes in each sample. If the $\Delta \mathrm{Ct}$ value between the two genes remains constant, then both genes are stable. However, if the $\Delta \mathrm{Ct}$ value fluctuates, then one or both genes have unstable expression. In different tissues, the results obtained by this method were similar to those obtained with the other methods, with a few exceptions. For example, $18 S r R N A$ was ranked the 4th most stable reference gene by this method (Figure 5A). However, this gene was ranked the most stable reference gene by geNorm, NormFinder and BestKeeper methods. Under salinity stress, RPL7 showed the least variation, followed by HRPT. The least stable gene in both experimental sets was GAPDH (Figure 5B).

\section{Recommended comprehensive ranking}

Based on the rankings results from four algorithms, the overall ranking of reference genes was obtained. The geometric mean of each reference gene ranking was calculated for the overall final ranking. For example, $R P L 7$ ranked the 4 th, 6 th, 3th, and 5th place during different tissues in geNorm, NormFinder, BestKeeper, and comparative $\triangle \mathrm{Ct}$ method, respectively. Then, the geometric mean of the four ranking numbers was calculated, thus for, RPL7 the geometric mean is $4.36\left[(4 \times 6 \times 3 \times 5)^{0.25}\right]$. The gene with the lowest geometric mean shows the highest stability. As shown in Table 4, in different tissues, $18 S r R N A>A C T B>R N A P$ ol $I I>E F 1 A>T U B A>R P L 7$ $>H R P T>B 2 M>G A P D H$. Under salinity stress, RPL7 $>$ RNAPol $I I>H R P T>T U B A>B 2 M>$ $18 S r R N A>E F 1 A>A C T B>G A P D H$.

\section{Discussion}

The qRT-PCR is a highly sensitive, specific and reproducible method for gene expression 
269 analysis. The optimal reference gene is constantly transcribed in different types of cells, tissues, and species and under various experimental conditions. However, the most stable reference gene to meet all conditions is almost non-existent. The selection of a proper reference gene is the precondition for the accurate analysis of the expression level of a target gene in quantitative realtime PCR. Thus far, the expression levels of the currently used reference genes showed large differences under various treatment conditions. For example, the expression level of GAPDH showed a significant difference in black rockfish(Sebastes schlegeli) during larvae developmental stages and tissue analysis (Ma et al., 2013). A number of common reference genes have been used without being validated. Therefore, to avoid unnecessary errors in the profiling of gene expression, the expression stability of 9 candidate reference genes in different tissues and under salinity stress was analyzed by four programs (geNorm, NormFinder, BestKeeper and comparative $\Delta \mathrm{Ct}$ method). The four types of algorithms showed that GAPDH was least stable gene in common. However, there are some differences in the ranking order of stability. For example, during different tissues, RPL7 was ranked the 4 th most stable reference gene by geNorm and 5 th by comparative $\Delta \mathrm{Ct}$ method but ranked 6th by NormFinder and 3rd by BestKeeper. In general, the differences in these results might be due to the different algorithms among these applications. Similar results have also been observed in several studies (Bower \& Johnston, 2009; Urbatzka et al., 2013). However, there is no consensus on which application is better to use.

In the present study, $18 S r R N A$ was most suitable gene in different tissues when using qRTPCR for RNA transcription analysis. Similarly, $18 S r R N A$ was one of the most stable genes in seven tissues of Nile tilapia (Yang et al., 2013), and EF 1 $\alpha, R p l 13 \alpha$ and $18 S$ rRNA were more suitable as a reference gene panel for zebrafish tissue analysis (Tang et al., 2007). Moreover, $18 S$ $r R N A$ was a classical reference gene and has been described as a preferable control (Blanquicett et al., 2002). Conversely, the study (Radonić et al., 2004; Fernandes et al., 2008) showed that $18 S$ $r R N A$ was not suitable for internal reference genes. $18 S r R N A$ transcription could display changes in gene expression related to the imbalance between messenger and ribosomal RNA content in rat mammary tumors (Solanas, Moral \& Escrich, 2001). In addition, $18 S$ rRNA had a markedly high transcription level compared to that of other genes, which indicates that cDNA samples need larger template dilutions within the dynamic range of qRT-PCR, particularly when the target gene expression level is weak. The transcript abundance of the reference gene may affect the results of gene expression (Filby \& Tyler, 2007). Nevertheless, the use of $18 S$ rRNA is highly recommended as an internal control standard in tissues for target gene expression, and ACTB may be an appropriate choice when the target gene is not abundant in expression level. Interestingly, in Asian seabass (Lates calcarifer) (Paria et al., 2016), ACTB and EF1A are the most stable genes across the tissues of normal animals and $18 S$ rRNA and EF1A are the best reference genes in bacteria challenged animals. This is roughly the same as the results of our present study. The slight difference may be due to differences in experimental conditions and the number of algorithm programs.

Salinity is one of the most important environmental factors for aquatic organisms. The transcription abundance was measured from low to high salinity. As a member of the ribosomal protein family, $R P L 7$ was considered a suitable gene in salinity stress in the present study. This 
310 gene was also confirmed in other studies. For example, RPL7 was the most stable gene in the liver

311 of zebrafish under bacterial expression. Varsamos (Varsamos et al., 2006) reported similar

312 findings in European seabass (Dicentrarchus labrax), showing that RPL17 was a valid candidate

313 references in seawater and following acclimation to fresh water. Similarly, L13a (RPL13a) are

314 recommended for qPCR normalization according to BestKeeper and NormFinder (Mitter et al.,

315 2009). For an optimal number of reference genes, geNorm analysis suggests the inclusion of one

316 or more genes for accurate normalization when the cut off range of the pairwise variation value is

317 above 0.15 . In the present study, the pairwise variation was above 0.15 in different tissues.

318 However, 0.15 is not an absolute cutoff value but rather an ideal value depending on the number

319 of genes and types of samples tested (Singh et al., 2015). We agree that more than one gene should

320 be used as a reference gene for calibration in the normalization process. Therefore, more genes

321 should be selected as candidate reference genes when studying the gene expression related to

322 various tissues. In addition, with in-depth whole genome sequencing, the acquisition of reference

323 gene will no longer be limited to a few traditional reference genes.

\section{Conclusion}

In the present study, we evaluated the stability of nine reference genes by using four programs and confirmed that $18 S$ rRNA and RPL7 were the most suitable single reference gene in spotted sea bass under normal and salinity stress conditions, respectively. During different tissues, $A C T B$ may be an appropriate choice when the target gene is not abundant in expression level. The best combination of reference genes was RPL7 and RNAPol II according to overall ranking under salinity stress. Overall, the present study provides valuable information about the reference genes of L. maculatus that could be used for gene expression normalization in other teleost species.

\section{Acknowledgments}

We are greatly appreciative of the laboratory members for assistance with feeding th e fish and collecting the tissue samples.

\section{References}

Andersen CL, Jensen JL, Ørntoft TF. 2004. Normalization of real-time quantitative reverse transcrip tion-PCR data: a model-based variance estimation approach to identify genes suited for normalization, applied to bladder and colon cancer data sets. Cancer research 64:5245-5250 DOI 10.1158/0008-5472. CAN-04-0496.

Berlinsky DL, Taylor JC, Howell RA, Bradley TM, Smith TI. 2004. The effects of temperature an $\mathrm{d}$ salinity on early life stages of black sea bass Centropristis striata. Journal of the World Aquacultur e Society 35:335-344 DOI 10.1111/j.1749-7345.2004.tb00097.x.

Blanquicett C, Johnson MR, Heslin M, Diasio RB. 2002. Housekeeping gene variability in normal and carcinomatous colorectal and liver tissues: applications in pharmacogenomic gene expression studie s. Analytical biochemistry 303:209-214 DOI 10.1006/abio.2001.5570.

Bower NI, Johnston IA. 2009. Selection of reference genes for expression studies with fish myogenic 
cell cultures. BMC Molecular Biology 10:80 DOI 10.1186/1471-2199-10-80.

Chen D, Pan X, Xiao P, Farwell MA, Zhang B. 2011. Evaluation and identification of reliable refe rence genes for pharmacogenomics, toxicogenomics, and small RNA expression analysis. Journal of ce llular physiology, 226(10), 2469-2477. DOI 10.1002/jcp.22725.

Dekkers BJ, Willems L, Bassel GW, van Bolderen-Veldkamp RP, Ligterink W, Hilhorst HW, Be ntsink L. 2012. Identification of reference genes for RT-qPCR expression analysis in Arabidopsis and tomato seeds. Plant and Cell Physiology 53:28-37 DOI 10.1093/pcp/pcr113.

Evans DH, Piermarini PM, Choe KP. 2005. The multifunctional fish gill: dominant site of gas exch ange, osmoregulation, acid-base regulation, and excretion of nitrogenous waste. Physiological reviews 8 5:97-177 DOI 10.1152/physrev.00050.2003.

Fernandes JM, Mommens M, Hagen Ø, Babiak I, Solberg C. 2008. Selection of suitable reference genes for real-time PCR studies of Atlantic halibut development. Comparative Biochemistry and Physi ology Part B: Biochemistry and Molecular Biology 150:23-32 DOI 10.1016/j.cbpb.2008.01.003.

Filby AL, Tyler CR. 2007. Appropriate 'housekeeping' genes for use in expression profiling the effec ts of environmental estrogens in fish. BMC molecular biology 8:10 DOI 10.1186/1471-2199-8-10.

Glare EM, Divjak M, Bailey MJ, Walters EH. 2002. $\beta$-Actin and GAPDH housekeeping gene expr ession in asthmatic airways is variable and not suitable for normalising mRNA levels. Thorax 57:765770 DOI 10.1136/thorax.57.9.765

Gutierrez L, Mauriat M, Guénin S, Pelloux J, Lefebvre JF, Louvet R, Rusterucci C, Moritz T, Guerineau F, Bellini C, Van Wuytswinkel O. 2008. The lack of a systematic validation of reference genes: a serious pitfall undervalued in reverse transcription-polymerase chain reaction (RT-PCR) analys is in plants. Plant biotechnology journal 6:609-618 DOI 10.1111/j.1467-7652.2008.00346.x.

Han YL, Hou CC, Du C, Zhu JQ. 2017. Molecular cloning and expression analysis of five heat sh ock protein 70 (HSP70) family members in Lateolabrax maculatus with Vibrio harveyi infection. Fish \& shellfish immunology 60:299-310 DOI 10.1016/j.fsi.2016.11.056.

Imsland AK, Foss A, Gunnarsson S, Berntssen MH, FitzGerald R, Bonga SW, Ham EV, Nævdal G, Stefansson SO. 2001. The interaction of temperature and salinity on growth and food conversion i n juvenile turbot (Scophthalmus maximus). Aquaculture 198:353-367 DOI 10.1016/S0044-8486(01)0050 7-5.

Katoh F, Shimizu A, Uchida K, Kaneko T. 2000. Shift of chloride cell distribution during early life stages in seawater-adapted killifish, Fundulus heteroclitus. Zoological science 17:11-18 DOI 10.2108/zs j.17.11.

Kim YU, Myoung JG, Kim YS, Han KH, Kang CB, Kim JK, Ryu JH. 2001. The marine fishes of Korea. Hanguel, Pusan 222.

Liu JX, Gao TX, Yokogawa K, Zhang YP. 2006. Differential population structuring and demographi c history of two closely related fish species, Japanese sea bass (Lateolabrax japonicus) and spotted se a bass (Lateolabrax maculatus) in Northwestern Pacific. Molecular phylogenetics and Evolution 39:799 -811. DOI 10.1016/j.ympev.2006.01.009.

Ma LM, Wang WJ, Liu CH, Yu HY, Wang ZG, Wang XB, Qi J, Zhang QQ. 2013. Selection of reference genes for reverse transcription quantitative real-time PCR normalization in black rockfish (Se bastes schlegeli). Marine genomics 11:67-73 DOI 10.1016/j.margen.2013.08.002. 
Mitter K, Kotoulas G, Magoulas A, Mulero V, Sepulcre P, Figueras A, Novoa B, Sarropoulou E - 2009. Evaluation of candidate reference genes for QPCR during ontogenesis and of immune-relevant tissues of European seabass (Dicentrarchus labrax). Comparative Biochemistry and Physiology Part B: Biochemistry and Molecular Biology 153:340-347 DOI 10.1016/j.cbpb.2009.04.009.

Pfaffl MW. 2001. A new mathematical model for relative quantification in real-time RT-PCR. Nucleic acids research 29:e45-e45 DOI 10.1093/nar/29.9.e45.

Pfaffl MW, Tichopad A, Prgomet C, Neuvians TP. 2004. Determination of stable housekeeping gen es, differentially regulated target genes and sample integrity: BestKeeper-Excel-based tool using pair-w ise correlations. Biotechnology letters 26:509-515 DOI 10.1023/B:BILE.0000019559.84305.47.

Paria A, Dong J, Babu PP, Makesh M, Chaudhari A, Thirunavukkarasu AR, Purushothaman C S, Rajendran KV. 2016. Evaluation of candidate reference genes for quantitative expression studies in Asian seabass (Lates calcarifer) during ontogenesis and in tissues of healthy and infected fishes. India $n$ Journal of Experimental Biology 54:597-605.

Radonić A, Thulke S, Mackay IM, Landt O, Siegert W, Nitsche A. 2004. Guideline to reference gene selection for quantitative real-time PCR. Biochemical and biophysical research communications 3 13:856-862 DOI 10.1016/j.bbrc.2003.11.177.

Silver N, Best S, Jiang J, Thein SL. 2006. Selection of housekeeping genes for gene expression stu dies in human reticulocytes using real-time PCR. BMC molecular biology 7:33 DOI 10.1186/1471-219 9-7-33.

Singh V, Kaul SC, Wadhwa R, Pati PK. 2015. Evaluation and selection of candidate reference gen es for normalization of quantitative RT-PCR in Withania somnifera (L.) Dunal. PloS one 10:e118860 DOI 10.1371/journal.pone.0118860.

Solanas M, Moral R, Escrich E. 2001. Unsuitability of using ribosomal RNA as loading control for Northern blot analyses related to the imbalance between messenger and ribosomal RNA content in rat mammary tumors. Analytical biochemistry 288:99-102 DOI 10.1006/abio.2000.4889.

Tandler A, Anav FA, Choshniak I. 1995. The effect of salinity on growth rate, survival and swimb ladder inflation in gilthead seabream, Sparus aurata, larvae. Aquaculture 135:343-353 DOI 10.1016/00 44-8486(95)01029-7.

Tang R, Dodd A, Lai D, McNabb WC, Love DR. 2007. Validation of zebrafish (Danio rerio) refer ence genes for quantitative real-time RT-PCR normalization. Acta biochimica et biophysica Sinica 39:3 84-390 DOI 10.1111/j.1745-7270.2007.00283.x.

Urbatzka R, Galante-Oliveira S, Rocha E, Castro LFC, Cunha I. 2013. Normalization strategies fo $\mathrm{r}$ gene expression studies by real-time PCR in a marine fish species, Scophthalmus maximus. Marine genomics 10:17-25 DOI 10.1016/j.margen.2013.02.001.

Vandesompele J, De Preter K, Pattyn F, Poppe B, Van Roy N, De Paepe A, Speleman F. 2002. Accurate normalization of real-time quantitative RT-PCR data by geometric averaging of multiple inter nal control genes. Genome biology 3:research0034-1 DOI 10.1186/gb-2002-3-7-research0034.

Varsamos S, Flik G, Pepin JF, Bonga SW, Breuil G. 2006. Husbandry stress during early life stag es affects the stress response and health status of juvenile sea bass, Dicentrarchus labrax. Fish \& she llfish immunology 20:83-96 DOI 10.1016/j.fsi.2005.04.005.

Wang ZP, Wang D, Wang CL, Xie WJ, Zhu YF, Chen XW. 2017. Transcriptome characterization 
430 of HPG axis from Chinese sea perch Lateolabrax maculatus. Journal of fish biology 91:1407-1418 D

431 OI 10.1111/jfb.13459.

432 Yang CG, Wang XL, Tian J, Liu W, Wu F, Jiang M, Wen H. 2013. Evaluation of reference gen 433 es for quantitative real-time RT-PCR analysis of gene expression in Nile tilapia (Oreochromis niloticu 434 s). Gene 527:183-192 DOI 10.1016/j.gene.2013.06.013.

435 Yokogawa K, Seki S. 1995. Morphological and genetic differences between Japanese and Chinese sea 436 bass of the genus Lateolabrax. Japanese journal of ichthyology 41:437-445 DOI 10.11369/jji1950.41.43 4377.

438 Yokogawa K. 2013. Nomenclatural reassessment of the sea bass Lateolabrax maculatus (McClelland, 439 1844) (Percichthyidae) and a redescription of the species. Biogeography 15:21-32.

440 Zhang XY, Wen HS, Wang HL, Ren YY, Zhao J, Li Y. 2017. RNA-Seq analysis of salinity stress 441 -responsive transcriptome in the liver of spotted sea bass (Lateolabrax maculatus). PloS one 12:e0173 442238 DOI 10.1371/journal.pone.0173238.

443 Zheng WJ, Sun L. 2011. Evaluation of housekeeping genes as references for quantitative real time R 444 T-PCR analysis of gene expression in Japanese flounder (Paralichthys olivaceus). Fish \& shellfish im 445 munology 30:638-645 DOI 10.1016/j.fsi.2010.12.014.

446 Zhong QW, Zhang QQ, Wang ZG, Qi J, Chen YJ, Li S, Sun YY, Li CM, Lan X. 2008. Expres 447 sion profiling and validation of potential reference genes during Paralichthys olivaceus embryogenesis. 448 Marine Biotechnology 10:310-318 DOI 10.1007/s10126-007-9064-7. 


\section{Figure 1}

Expression levels of candidate reference genes in different tissues (A) and salinity stress (B).

The boxes indicate the 1st and 3rd quartiles. The vertical lines (whiskers) represent the maximum and minimum values.
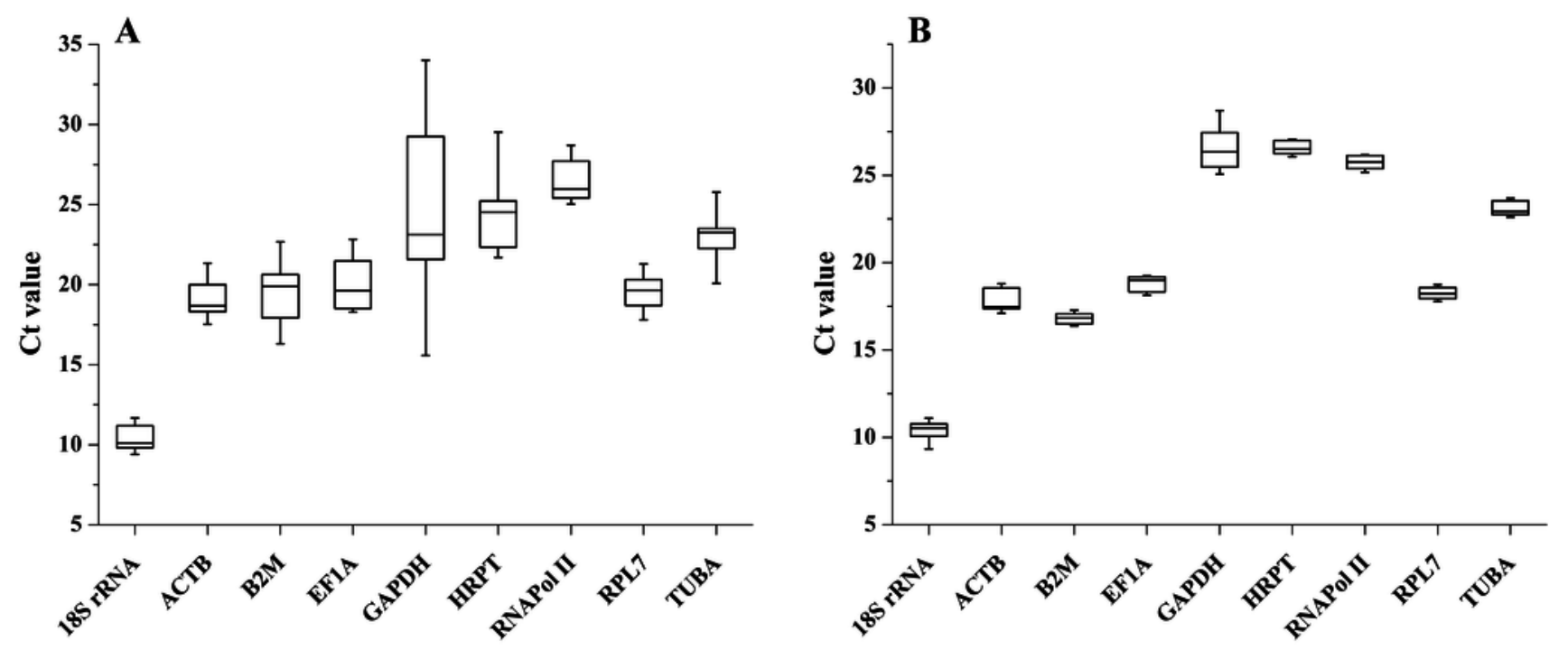
Figure 2

Average expression stability values of the candidate reference genes (A) in different tissues and (B) under salinity stress analyzed by geNorm.
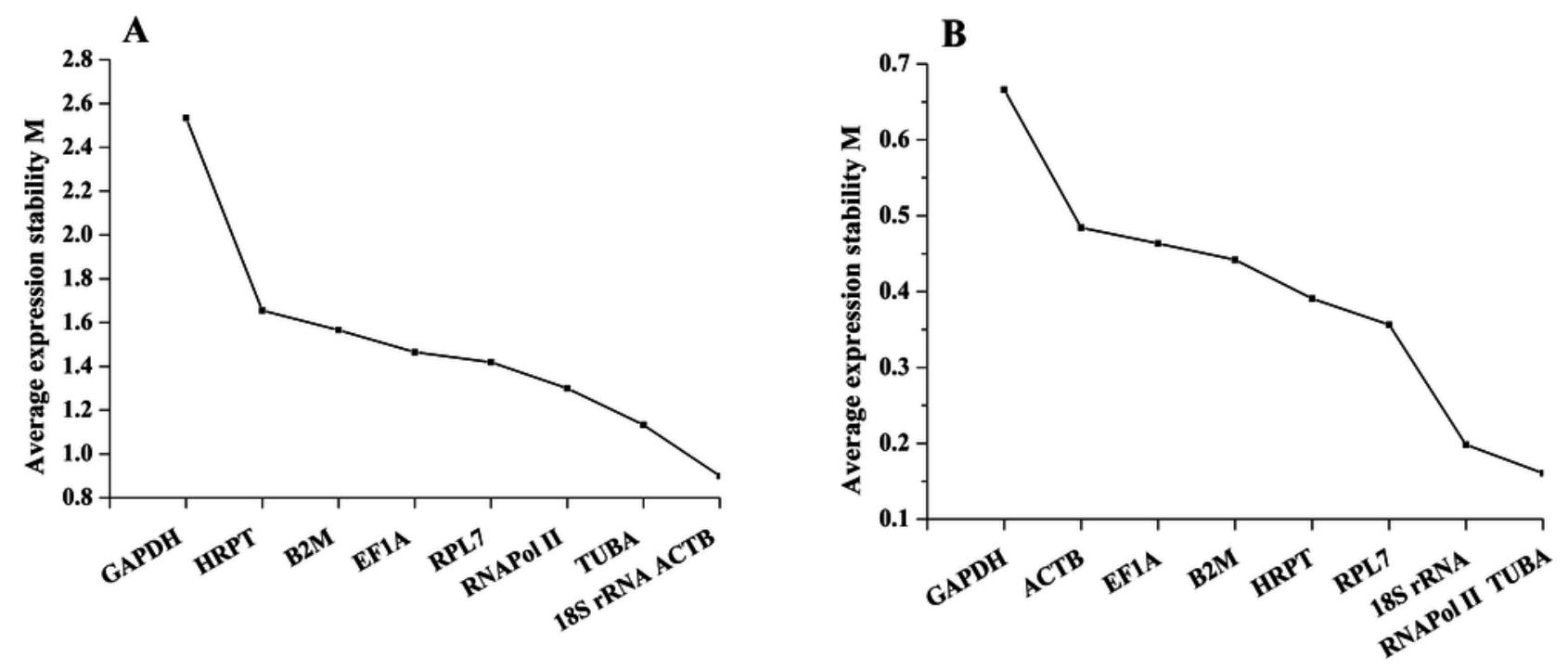
Figure 3

The number of reference genes calculated by geNorm in different tissues $(A)$ and under salinity stress (B).

The dotted lines represent the cut-off limit value of 0.15 .
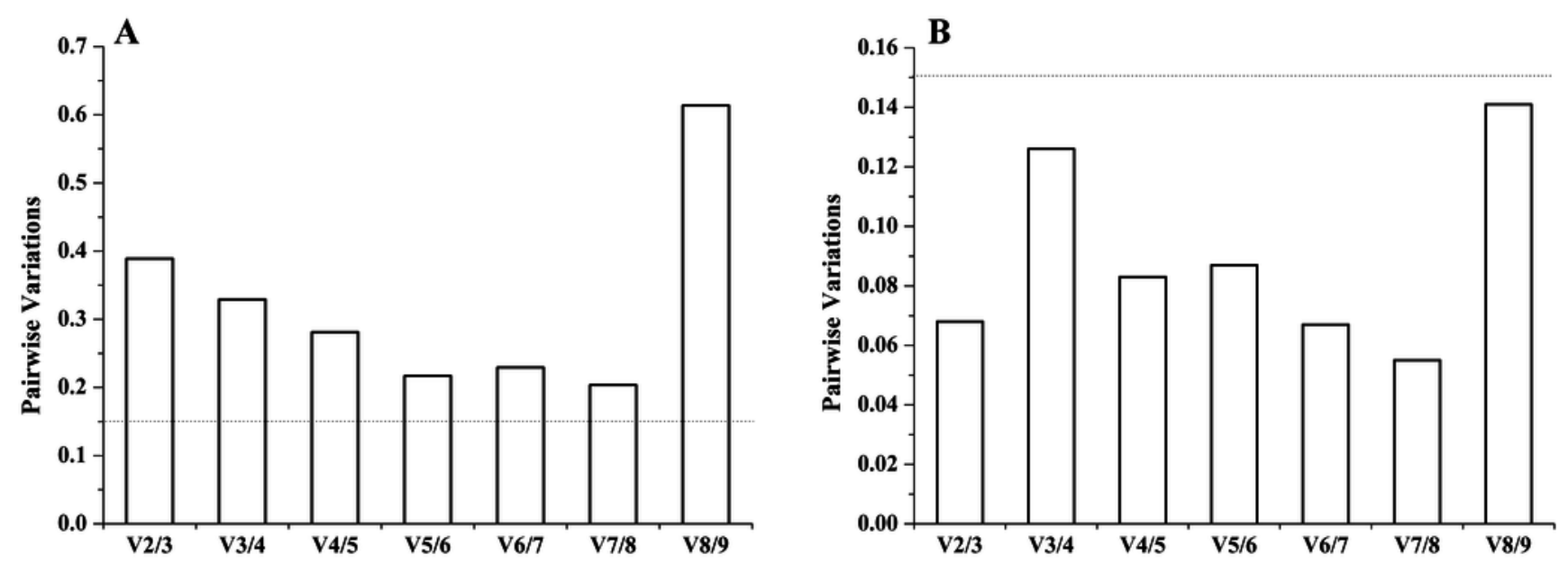
Figure 4

Average expression stability values of the candidate reference genes in different tissues (A) and under salinity stress (B) analyzed by NormFinder.
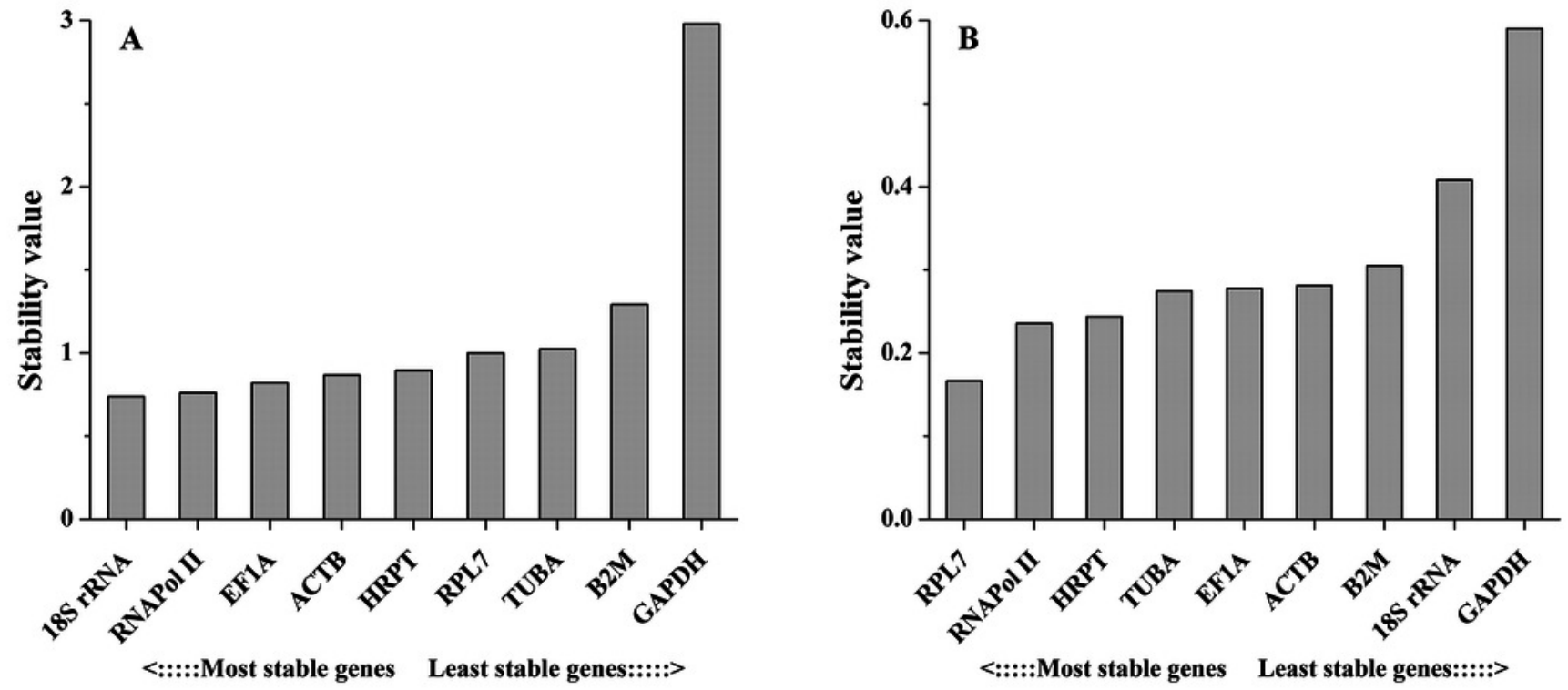
Figure 5

Stability values of the candidate reference genes in different tissues $(A)$ and under salinity stress (B) analyzed by Comparative $\Delta \mathrm{Ct}$ method.
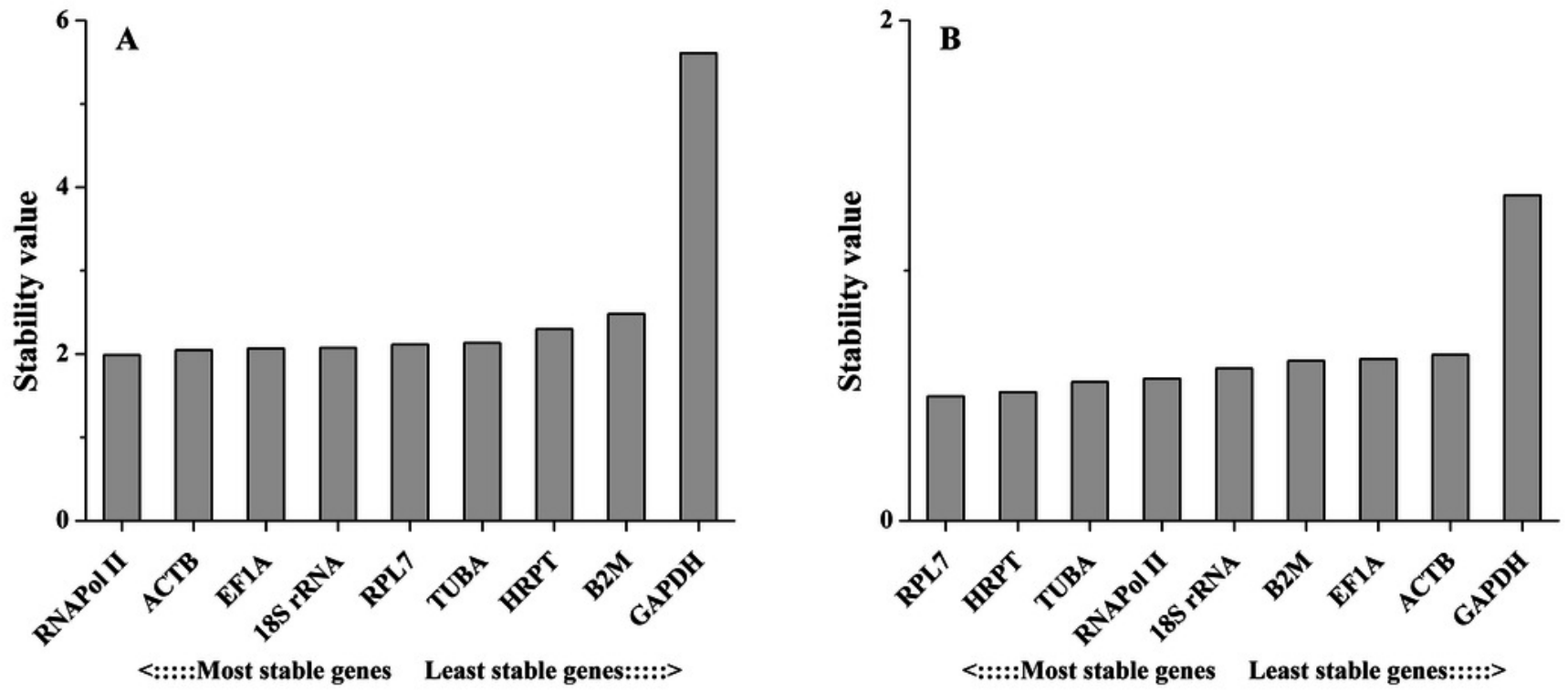


\section{Table $\mathbf{1}$ (on next page)}

Summary of reference genes in this study. 
1 Table 1. Summary of reference genes in this study

\begin{tabular}{llc}
\hline Abbreviation & Reference gene name & NCBI accession number \\
\hline$H P R T$ & $\begin{array}{l}\text { Hypoxanthine guanine } \\
\text { phosphoribosyl transferase1 } \\
\text { Glyceraldehyde-3-phosphate } \\
\text { dehydrogenase }\end{array}$ & MH181802 \\
GAPDH & Elongation factor-1- $\alpha$ & $\mathrm{MH} 181801$ \\
EF1A & $\alpha$-Tubulin & $\mathrm{MH} 181800$ \\
$T U B A$ & Ribosomal protein L7 & $\mathrm{MH} 181805$ \\
RPL7 & RNA polymerase II subunit C & $\mathrm{MH} 181803$ \\
RNAPol II & $\beta$-2-microglobulin & $\mathrm{MH} 181798$ \\
B2M & $\beta$-Actin & $\mathrm{MH} 181804$ \\
$18 S$ rRNA & 18S ribosomal RNA & $\mathrm{JN} 211898$ \\
\hline
\end{tabular}

2 
Table 2 (on next page)

Primer sequences, product sizes and PCR efficiencies of the selected genes. 
1 Table 2. Primer sequences, product sizes and PCR efficiencies of the selected genes.

\begin{tabular}{|c|c|c|c|c|}
\hline $\begin{array}{l}\text { Gene } \\
\text { name }\end{array}$ & $5^{\prime}-3^{\prime}$ primer sequence & $\begin{array}{l}\text { Amplicon size } \\
\text { (bp) }\end{array}$ & $\begin{array}{l}\text { Primer } \\
\text { Efficiency }(\%)\end{array}$ & $\begin{array}{l}\text { Correlation } \\
\text { coefficients }\end{array}$ \\
\hline HPRT-F & TGCTCAAAGGGGGTTACAAG & 117 & 105.74 & 0.9966 \\
\hline HPRT-R & AGTAGCTCTTGAGGCGGATG & & & \\
\hline GAPDH-F & AGCTCAATGGCAAGCTGACT & 125 & 94.16 & 0.9994 \\
\hline GAPDH-R & GGCCTTCACAACCTTCTTGA & & & \\
\hline EF1A-F & GCAAGTTCAGGGAGCTCATC & 121 & 99.44 & 0.9976 \\
\hline EF1A-R & ATTGGCTTCTGTGGAACCAG & & & \\
\hline TUBA-F & AGGTCTCCACAGCAGTAGTAGAGC & 89 & 106.67 & 0.9993 \\
\hline TUBA-R & GTCCACCATGAAGGCACAGTCG & & & \\
\hline RPL7-F & ACCCCAACCTGAAGTCTGTG & 121 & 101.11 & 0.9986 \\
\hline RPL7-R & ATGCCATATTTGCCAAGAGC & & & \\
\hline RNAPol II-F & GTCAGGAACTACGGCTCAGG & 117 & 102.88 & 0.9975 \\
\hline RNAPol II-R & TGTGCCTCAGTGCATTGTCT & & & \\
\hline B2M-F & GACCTGGCCTTCAAACAGAA & 125 & 102.05 & 0.9993 \\
\hline $\mathrm{B} 2 \mathrm{M}-\mathrm{R}$ & TCCCAGGCGTAATCTTTGAC & & & \\
\hline ACTB-F & CAACTGGGATGACATGGAGAAG & 114 & 99.46 & 0.9981 \\
\hline ACTB-R & TTGGCTTTGGGGTTCAGG & & & \\
\hline 18S rRNA-F & GGGTCCGAAGCGTTTACT & 179 & 94.31 & 0.9969 \\
\hline 18S rRNA-R & TCACCTCTAGCGGCACAA & & & \\
\hline
\end{tabular}

2 


\section{Table 3(on next page)}

Descriptive statistics of 9 candidate reference genes based on their quantification cycle values analyzed by BestKeeper. 
1 Table 3. Descriptive statistics of 9 candidate reference genes based on their quantification cycle values 2 analyzed by BestKeeper.

\begin{tabular}{|c|c|c|c|c|c|c|c|c|c|c|}
\hline & \multirow[t]{2}{*}{ Parameters } & \multicolumn{9}{|c|}{ Genes } \\
\hline & & $18 S r R N A$ & $A C T B$ & $B 2 M$ & EF1A & $G A P D H$ & $H R P T$ & RNAPolII & $R P L 7$ & $T U B A$ \\
\hline \multirow{6}{*}{$\begin{array}{c}\text { Different } \\
\text { tissues } n=90\end{array}$} & Geo mean $[\mathrm{CP}]$ & 10.335 & 19.008 & 19.451 & 19.979 & 24.277 & 24.392 & 26.372 & 19.514 & 22.896 \\
\hline & Ar mean $[\mathrm{CP}]$ & 10.360 & 19.038 & 19.541 & 20.038 & 24.828 & 24.481 & 26.399 & 19.542 & 22.941 \\
\hline & Min [CP] & 9.402 & 17.527 & 16.305 & 18.275 & 15.573 & 21.691 & 25.023 & 17.809 & 20.080 \\
\hline & $\operatorname{Max}[\mathrm{CP}]$ & 11.670 & 21.344 & 22.671 & 22.831 & 34.015 & 29.517 & 28.703 & 21.293 & 25.779 \\
\hline & Std dev $[ \pm \mathrm{CP}]$ & 0.628 & 0.877 & 1.453 & 1.366 & 4.357 & 1.498 & 1.059 & 0.898 & 1.035 \\
\hline & $\mathrm{CV}[\% \mathrm{CP}]$ & 6.061 & 4.604 & 7.436 & 6.817 & 17.550 & 6.121 & 4.011 & 4.594 & 4.511 \\
\hline \multirow{6}{*}{$\begin{array}{c}\text { Different } \\
\text { salinities } n=36\end{array}$} & Geo mean $[\mathrm{CP}]$ & 10.376 & 17.812 & 16.790 & 18.817 & 26.494 & 26.480 & 25.769 & 18.095 & 23.136 \\
\hline & Ar mean $[\mathrm{CP}]$ & 10.386 & 17.821 & 16.793 & 18.821 & 26.517 & 26.482 & 25.772 & 18.096 & 23.140 \\
\hline & $\operatorname{Min}[\mathrm{CP}]$ & 9.661 & 17.262 & 16.421 & 18.163 & 25.222 & 26.145 & 25.218 & 17.856 & 22.584 \\
\hline & $\operatorname{Max}[\mathrm{CP}]$ & 10.828 & 18.783 & 17.204 & 19.208 & 28.133 & 26.936 & 26.106 & 18.418 & 23.631 \\
\hline & Std dev $[ \pm \mathrm{CP}]$ & 0.363 & 0.481 & 0.257 & 0.329 & 1.016 & 0.285 & 0.306 & 0.202 & 0.396 \\
\hline & $\mathrm{CV}[\% \mathrm{CP}]$ & 3.491 & 2.697 & 1.532 & 1.749 & 3.830 & 1.078 & 1.188 & 1.114 & 1.710 \\
\hline
\end{tabular}

3 
Table 4(on next page)

Ranking of candidate reference genes by geNorm, NormFinder, BestKeeper, comparative $\Delta \mathrm{Ct}$ method, and overall rank. 
Table 4. Ranking of candidate reference genes by geNorm, NormFinder, BestKeeper, comparative $\Delta C t$ method, and overall rank.

2

\begin{tabular}{|c|c|c|c|c|c|c|}
\hline Conditions & Ranking & $\begin{array}{l}\text { geNorm } \\
\text { rank }\end{array}$ & $\begin{array}{l}\text { NormFinder } \\
\text { rank }\end{array}$ & $\begin{array}{l}\text { BestKeeper } \\
\text { rank }\end{array}$ & $\begin{array}{l}\Delta \mathrm{Ct} \\
\text { rank }\end{array}$ & $\begin{array}{l}\text { overall } \\
\text { rank }\end{array}$ \\
\hline \multirow[t]{9}{*}{ Tissue } & 1 & $18 S$ rRNA / ACTB & $18 S r R N A$ & $18 S r R N A$ & RNAPol II & $18 S r R N A$ \\
\hline & 2 & $T U B A$ & RNAPol II & $A C T B$ & $A C T B$ & $A C T B$ \\
\hline & 3 & RNAPol II & $E F 1 A$ & $R P L 7$ & $E F 1 A$ & RNAPol II \\
\hline & 4 & $R P L 7$ & $A C T B$ & $T U B A$ & $18 S r R N A$ & $E F 1 A$ \\
\hline & 5 & $E F 1 A$ & $H R P T$ & RNAPol II & RPL7 & $T U B A$ \\
\hline & 6 & $B 2 M$ & RPL7 & $E F 1 A$ & $T U B A$ & RPL7 \\
\hline & 7 & $H R P T$ & $T U B A$ & $H R P T$ & $H R P T$ & $H R P T$ \\
\hline & 8 & $G A P D H$ & $B 2 M$ & $B 2 M$ & $B 2 M$ & $B 2 M$ \\
\hline & 9 & & $G A P D H$ & $G A P D H$ & $G A P D H$ & GAPDH \\
\hline \multirow[t]{9}{*}{ Salinity stress } & 1 & RNAPol II / TUBA & $R P L 7$ & $R P L 7$ & $R P L 7$ & $R P L 7$ \\
\hline & 2 & $18 S r R N A$ & RNAPol II & $B 2 M$ & $H R P T$ & RNAPol II \\
\hline & 3 & $R P L 7$ & $H R P T$ & $H R P T$ & $T U B A$ & $H R P T$ \\
\hline & 4 & $H R P T$ & $T U B A$ & RNAPol II & RNAPol II & $T U B A$ \\
\hline & 5 & $B 2 M$ & $E F 1 A$ & $E F 1 A$ & $18 S r R N A$ & $B 2 M$ \\
\hline & 6 & $E F 1 A$ & $A C T B$ & $18 S r R N A$ & $B 2 M$ & $18 S r R N A$ \\
\hline & 7 & $A C T B$ & $B 2 M$ & $T U B A$ & $E F 1 A$ & $E F 1 A$ \\
\hline & 8 & $G A P D H$ & $18 S r R N A$ & $A C T B$ & $A C T B$ & $A C T B$ \\
\hline & 9 & & $G A P D H$ & $G A P D H$ & $G A P D H$ & GAPDH \\
\hline
\end{tabular}

3 